\title{
AVALIAÇÃO DA IDADE E CONCENTRAÇÃO DA MICROALGA CHLAMYDOMONAS REINHARDTII POTENCIALMENTE UTILIZADAS NA PRODUÇÃO DE HIDROGÊNIO
}

\author{
R. L. COSTA, M. C. SOARES, J. S. FERREIRA, V. L. CARDOSO, F. R. X. BATISTA
}

Universidade Federal de Uberlândia, Departamento de Engenharia Química

E-mail para contato: frxbatista@feq.ufu.br

\begin{abstract}
RESUMO - A produção de hidrogênio $\left(\mathrm{H}_{2}\right)$ através de rota biológica tem sido observada nos últimos anos como uma alternativa atraente ao uso de combustíveis de origem fóssil. Este estudo avaliou a influência de parâmetros de crescimento (idade e concentração de inóculo) da alga verde Chlamydomonas reinhardtii assim como a influência do enxofre na produção de $\mathrm{H}_{2}$. As fermentações foram realizadas em reatores com $37,5 \mathrm{~mL}$ de volume útil e mantidas em estufa germinadora a $25^{\circ} \mathrm{C}$ com foto-período de $12 \mathrm{~h}$ e luminosidade de $2200 \mathrm{lux}$. O meio basal TAP foi utilizado. Parâmetros como o monitoramento do consumo da fonte de carbono (ácido acético), além da observação da síntese de metabólitos (ácidos orgânicos e etanol) também foram avaliados. Os resultados mostraram que a idade e a concentração de inóculo mais adequadas para a produção de $\mathrm{H}_{2}$ foram respectivamente o décimo dia de cultivo e $0,20 \mathrm{~g}$ células/L. De forma complementar, com a variação do teor de enxofre no meio basal foi possível se observar uma pequena diferença na produção de $\mathrm{H}_{2}$ para duas das concentrações de inóculo avaliadas. Para $0,10 \mathrm{~g} / \mathrm{L}$ o teor que propiciou uma maior produção do produto-alvo foi o de $10 \mathrm{mg}$, enquanto que para $0,20 \mathrm{~g} / \mathrm{L}$ foi verificado que $25 \mathrm{mg}$ de enxofre no meio resultaram em $8 \%$ a mais de $\mathrm{H}_{2}$.
\end{abstract}

\section{INTRODUÇÃO}

As microalgas têm se destacado nos últimos anos na área acadêmica e na indústria em virtude de seu potencial para a produção de biocombustíveis e derivados (Tevatia et al., 2012). Estes indivíduos são capazes de absorver a luz solar e convertê-la em produtos de elevado valor agregado como lipídios, proteínas (Amin, 2009), dentre outros. Neste contexto, destaca-se a alga verde unicelular Chlamydomonas reinhardtii que utiliza potencialmente a energia luminosa para produzir $\mathrm{H}_{2}$ através de rota enzimática. É sabido que esta alga produz o $\mathrm{H}_{2}$ em maior teor em condições de anoxia, uma vez que o oxigênio produzido durante a fotossíntese inibe a ação da enzima [FeFe]-hidrogenase responsável pelo fenômeno. Estudos demonstraram que resíduos de oxigênio da ordem de $2 \%$ podem desencadear este processo inibitório (Yang et al., 2014). Ainda neste contexto, Kosourov et al. (2007) mostraram que em um sistema contínuo a foto-produção de $\mathrm{H}_{2}$ por $C$. reinhardtii foi observada após a 
incubação da cultura por alguns dias na ausência de sulfato (enxofre). Segundo os autores, a supressão de enxofre no meio causa uma parcial e reversível inativação da evolução fotossintética do oxigênio nas algas, resultando assim no estabelecimento de anaerobiose no sistema. Tal condição favoreceu a expressão da [FeFe]-hidrogenase nas células e a produção de $\mathrm{H}_{2}$. Já Yang et al. (2014) utilizaram a privação de enxofre para proporcionar a alga uma diminuição da atividade do fotossistema II (PSII) e o aumento da taxa de respiração. Tal observação também tornou o sistema anaeróbio e com isso a hidrogenase pode ser induzida de maneira a catalisar a produção de $\mathrm{H}_{2}$ (Das e Veziroglu, 2001; Kosourov et al., 2002; Tamburic et al., 2011). É importante salientar que as algas utilizam a energia luminosa para gerar elétrons que são transferidos para uma molécula de ferrodoxina, tomando a sua forma reduzida. Posteriormente, a enzima hidrogenase combina os prótons $\left(\mathrm{H}^{+}\right)$do meio com os elétrons doados pela ferrodoxina reduzida, para formar e liberar $\mathrm{H}_{2}$ (Hallenbeck e Benemann, 2002). Assim, no intuito de desenvolver processos que melhorem a produção deste biocombustível utilizando a alga verde $C$. reinhadtii, este estudo investigou o efeito da idade e da concentração celular de inóculo. De forma adicional, a influência do teor de enxofre no meio e a síntese de subprodutos do metabolismo também foram avaliadas.

\section{MATERIAIS E MÉTODOS}

\subsection{Alga Verde, Meio de Cultivo e Condições de Pré-cultura}

A alga verde Chlamydomonas reinhardtii cc-124 foi adquirida do banco canadense Chlamydomonas Resource Center. Para a manutenção e pré-cultura, o meio basal Tris Acetate Phosphate - TAP (Andersen, 2005), com pH inicial ajustado para 7, foi utilizado. Cerca de $250 \mathrm{~mL}$ da suspensão celular foi cultivada em frascos erlenmeyer de $500 \mathrm{~mL}$. Para o subcultivo, o mesmo volume de meio fresco foi adicionado. Os frascos foram então mantidos em uma incubadora dotada de controle de temperatura de $25^{\circ} \mathrm{C}$ e foto-período de $12 \mathrm{~h}$, sem agitação mecânica. A intensidade luminosa foi ajustada para 2200lux.

\subsection{Supressão de Enxofre e Análise da Idade e Concentração do Inóculo}

As algas produzem $\mathrm{H}_{2}$ na ausência de enxofre (Das e Veziroglu, 2001). Neste contexto, o meio TAP teve este componente suprimido, sendo os sulfatos substituídos por quantidades equivalentes de sais de cloreto. Para a determinação da idade de inóculo que otimizasse a produção de $\mathrm{H}_{2}$, a concentração celular de $0,10 \mathrm{~g} / \mathrm{L}$ foi fixada e as idades de 5,10 e 15 dias avaliadas. Inicialmente, as algas foram centrifugadas à $8000 \mathrm{rpm}$ por $15 \mathrm{~min}$, lavadas com água deionizada e centrifugadas por duas vezes. A biomassa obtida foi reativada em meio fresco TAP sem enxofre, com $\mathrm{pH}$ de 7 , em reatores de $50 \mathrm{~mL}$, sendo o volume útil de $37,5 \mathrm{~mL}$. Argônio foi purgado no sistema para remover o oxigênio. Os frascos foram lacrados e selados e incubados na mesma condição da pré-cultura. Seringas $(10 \mathrm{~mL})$ foram introduzidas no selo do lacre de maneira a coletar o biogás produzido no experimento. De forma adicional, três concentrações iniciais de células $(0,05,0,10$ e 0,20g/L), utilizando inóculo com 10 dias de 
idade, foram avaliadas na produção de $\mathrm{H}_{2}$. $\mathrm{O}$ mesmo procedimento descrito anteriormente no que se refere ao preparo e execução do sistema foto fermentativo foi adotado.

\subsection{Análise de Diferentes Teores de Enxofre no Meio de Cultivo}

Uma vez observada a necessidade da existência de uma quantidade residual de enxofre no meio para a verificação da produção de $\mathrm{H}_{2}$, diferentes concentrações deste componente foram testadas. Esta verificação foi realizada para duas concentrações de inóculo $(0,10$ e 0,20g/L) com 10d de idade. Um cálculo preliminar mostrou que em sua composição original o meio TAP apresentava no total cerca de $50 \mathrm{mg}$ de componentes sulfurados. $\mathrm{O} \mathrm{MgSO}_{4} .7 \mathrm{H}_{2} \mathrm{O}$ contribuia isoladamente com cerca de $80 \%$ deste valor. Assim, a estratégia adotada para a verificação da influência do teor de enxofre na produção de $\mathrm{H}_{2}$ consistiu do preparo do meio TAP contendo quantidades diferenciadas deste sal $(0,10,25$ e $50 \mathrm{mg})$.

\subsection{Metodologia Analítica}

A concentração celular foi determinada através do método gravimétrico, correlacionando a concentração de sólidos voláteis $(\mathrm{SV})$ da biomassa de alga com a absorbância observada em uma densidade óptica de 665nm (VVmini-1240, UV-VIS Spectrophotometer). As concentrações de ácidos orgânicos e etanol foram determinados em HPLC (Shimadzu modelo LC-20A Proeminência, Supelcogel, Coluna C-610H), em que os componentes foram detectados por UV. A temperatura da coluna foi de $32^{\circ} \mathrm{C}$ e uma solução aquosa de $\mathrm{H}_{3} \mathrm{PO}_{4}(0,1 \%)$ foi usada para a eluição, mantida a vazão de $0,5 \mathrm{~mL} / \mathrm{min}$. É importante salientar que o sobrenadante celular utilizado para tal foi previamente autoclavado, centrifugado (8000rpm por $15 \mathrm{~min}$ ) e diluído (1:10). Só então foi filtrado e injetado no sistema de detecção. Já o biogás produzido foi analisado em um cromatográfico à gás (GC 17A Shimadzu), contendo uma coluna capilar Carboxen $1010 \mathrm{com} 30 \mathrm{~m}$ de comprimento e diâmetro interno de $0,53 \mathrm{~mm}$. A temperatura do injetor foi mantida em $230^{\circ} \mathrm{C}$, enquanto que a coluna e o detector em 32 e $230^{\circ} \mathrm{C}$, respectivamente.

\section{RESULTADOS E DISCUSSÕES}

\subsection{Avaliação da Idade de Inóculo}

Para a identificação da idade de inóculo adequada para a produção de $\mathrm{H}_{2}$, uma concentração inicial de células de $0,10 \mathrm{~g} / \mathrm{L}$ foi fixada, uma vez estabelecida a supressão de enxofre no meio basal TAP. Os resultados estão apresentados na Tabela 1. Em todos os casos, após 5 dias de fermentação, a produção de biogás foi observada, contudo, $\mathrm{H}_{2}$ não foi detectado. Kim et al. (2006) observaram que as células de $C$. reinhardtii podem produzir $\mathrm{H}_{2}$ quando 7 dias de idade de inóculo são empregados. No entanto, nos estudos realizados pelos pesquisadores uma variação na composição de enxofre no meio foi simultaneamente utilizada e o efeito isolado da influência da idade de inóculo na produção de $\mathrm{H}_{2}$ não foi determinado. Ressalta-se que a privação de enxofre por longos períodos pode ocasionar alterações 
metabólicas importantes nas algas, como a redução das taxas fotossintéticas que resultam na diminuição do oxigênio no meio, enquanto que os níveis de respiração são mantidos, fato que torna a cultura anaeróbia. Esta estratégia envolve o uso de energia luminosa para haver a quebra da água, gerando adenosina trifosfato e hidrogênio, e a degradação do amido em ácidos fórmico, acético, málico, etanol, e dióxido de carbono (Tamburic et al., 2011).

Tabela 1 -Concentração final de células e volume de biogás obtidos em 5 dias de fermentação. A concentração inicial de células utilizada foi de $0,10 \mathrm{~g} / \mathrm{L}$

\begin{tabular}{|c|c|c|}
\hline Idade de Inóculo $(\mathbf{d})$ & Concentração celular final $(\mathbf{g} / \mathbf{L})$ & Biogás $(\mathbf{m L})$ \\
\hline $\mathbf{5}$ & 0,19 & 0,10 \\
\hline $\mathbf{1 0}$ & 0,18 & 7,80 \\
\hline $\mathbf{1 5}$ & 0,12 & 1,00 \\
\hline
\end{tabular}

Os ácidos orgânicos produzidos pelas algas em culturas propagadas a partir de diferentes idades de inóculo (5, 10 e 15 dias) foram obtidos da análise do sobrenadante celular e os resultados podem ser encontrados na Tabela 2. Entretanto, é importante salientar que o ácido acético estava presente na composição original do meio TAP a 17,4 mmol/L.

Tabela 2 - Concentrações de ácidos obtidas em 5 dias de fermentação. A concentração inicial de células utilizada foi de $0,10 \mathrm{~g} / \mathrm{L}$

\begin{tabular}{|c|c|c|c|c|}
\hline $\begin{array}{c}\text { Idade do inóculo } \\
(\mathbf{g} / \mathbf{L})\end{array}$ & $\begin{array}{c}\text { Ácido Acético } \\
(\mathbf{m m o l} / \mathbf{L})\end{array}$ & $\begin{array}{c}\text { Ácido Propiônico } \\
(\mathbf{m m o l} / \mathbf{L})\end{array}$ & $\begin{array}{c}\text { Ácido Butírico } \\
(\mathbf{m m o l} / \mathbf{L})\end{array}$ & $\begin{array}{c}\text { Etanol } \\
(\mathbf{m m o l} / \mathbf{L})\end{array}$ \\
\hline $\mathbf{5}$ & 0,00 & 0,00 & 0,00 & 0,00 \\
\hline $\mathbf{1 0}$ & 30,65 & 0,07 & 0,00 & 0,00 \\
\hline $\mathbf{1 5}$ & 38,41 & 0,014 & 0,00 & 0,00 \\
\hline
\end{tabular}

Observando os dados encontrados nas Tabela 1 e 2 pode-se sugerir que para a idade de 5 dias, o ácido acético inicial foi utilizado para o crescimento celular, sendo o comportamento da alga caracterizado como heterotrófico. Na fase avaliada, um crescimento de $90 \%$ da alga foi observado, com um desvio padrão entre amostras de $0,40 \times 10^{-3}$. Já para a idade de 10 dias, o ácido acético atingiu no meio $30,7 \mathrm{mmol} / \mathrm{L}$, sendo observada também a presença do ácido propriônico no meio. Nesta condição um crescimento celular de $80 \%$, com um desvio padrão entre amostra de $2,29 \times 10^{-2}$ foi verificado. Para a idade de 15 dias, ácido acético produzido $(38,41 \mathrm{mmol} / \mathrm{L})$ e um desvio padrão entre amostras de $1,23 \times 10^{-2}$ foi observado. Contudo, nesta condição as algas cresceram somente $20 \%$. O desvio padrão calculado foi de $2,87 \times 10^{-2}$.

\subsection{Avaliação da Concentração Celular}

Visando a potencialização da produção de hidrogênio, a avaliação do efeito da concentração inicial de células foi realizada. Foram testadas as concentrações de 0,05, 0,10 e $0,20 \mathrm{~g} / \mathrm{L}$ de algas. Neste ensaio, o tempo de fermentação (5 dias) foi mantido e a idade de inóculo de 10 dias foi utilizada. Observa-se neste período a produção de biogás, que quando analisado, revelou a presença de hidrogênio em pequenas concentrações. Não sendo possível, 
portanto sua quantificação. Os principais produtos do metabolismo sintetizados nas condições avaliadas estão apresentados na Tabela 3.

Tabela 3 - Concentrações de ácidos orgânicos obtidas após 5 dias de fermentação em culturas nas quais a idade de inóculo foi de 10 dias

\begin{tabular}{|c|c|c|c|c|}
\hline $\begin{array}{c}\text { Concentração de } \\
\text { inoculo (g/L) }\end{array}$ & $\begin{array}{c}\text { Ácido Acético } \\
(\mathbf{m m o l} / \mathbf{L})\end{array}$ & $\begin{array}{c}\text { Ácido Propiônico } \\
\text { (mmol/L) }\end{array}$ & $\begin{array}{c}\text { Ácido Butírico } \\
(\mathbf{m m o l} / \mathbf{L})\end{array}$ & $\begin{array}{c}\text { Etanol } \\
(\mathbf{m m o l} / \mathbf{L})\end{array}$ \\
\hline $\mathbf{0 , 0 5}$ & 57,01 & 0,10 & 0,00 & 482,0 \\
\hline $\mathbf{0 , 1 0}$ & 30,65 & 0,07 & 0,00 & 0,00 \\
\hline $\mathbf{0 , 2 0}$ & 59,79 & 0,07 & 0,00 & 359,3 \\
\hline
\end{tabular}

Conforme a Tabela 3 , para a concentração de $0,05 \mathrm{~g} / \mathrm{L}$ da alga, a concentração final de ácido acético observada no meio foi de $57,01 \mathrm{mmol} / \mathrm{L}$, tendo um desvio padrão entre as replicatas de $3,31 \times 10^{-3}$. Nesta condição também se observa a síntese de ácido propiônico e etanol, no qual o desvio observado entre as replicatas foi de $8,43 \times 10^{-5}$ e $6,39 \times 10^{-2}$, respectivamente. Para uma concentração de $0,10 \mathrm{~g} / \mathrm{L}$ observou-se uma concentração final de $30,65 \mathrm{mmol} / \mathrm{L}$ de ácido acético, com desvio padrão de 3,16 $\times 10^{-2}$. Este caso também apresentou a produção de ácido propiônico, sendo o desvio padrão de $1,37 \times 10^{-2}$. No último experimento com uma concentração de inóculo de $0,20 \mathrm{~g} / \mathrm{L}$, a produção de ácido acético total foi de $59,79 \mathrm{mmol} / \mathrm{L}$, sendo que o desvio padrão entre as replicatas foi de $0,96 \times 10^{-3}$. Ácido propiônico e etanol também foram identificados na amostra, com desvio padrão de $2,66 \times 10^{-5}$ e $5,9 \times 10^{-2}$, respectivamente. Mus et al. (2007) relatou que a formação de etanol durante a fotofermentação por Chlamydomonas ocorre a partir da redução da acetil-CoA, resultando na oxidação de duas moléculas de NADH. Os autores salientam também que incrementos nos níveis de ADH1 mRNA ocorrem durante o período de anoxia. Assim, o piruvato pode ser também convertido a etanol via PDC1 (piruvato decarboxilase) e na rota da enzima álcool desidrogenase (ADH), verifica-se a produção de etanol e também a oxidação de um NADH. Já as concentrações finais de células podem ser observadas na Tabela 4. O crescimento acentuado das algas foi observado para uma concentração de inóculo de $0,10 \mathrm{~g} / \mathrm{L}$ (75\%), enquanto que para a concentração de $0,05 \mathrm{~g} / \mathrm{L}$ houve um crescimento de $14 \%$. Já para a última concentração avaliada $(0,20 \mathrm{~g} / \mathrm{L})$, não houve crescimento celular e sim uma redução no número de células de $22,5 \%$.

Tabela 4 - Concentração final de células e volume de biogás obtidos em 5 dias de fermentação em culturas nas quais a idade de inóculo foi de 10 dias

\begin{tabular}{|c|c|c|}
\hline Concentração celular inicial $(\mathbf{d})$ & Concentração celular final $(\mathbf{g} / \mathbf{L})$ & Biogás $(\mathbf{m L})$ \\
\hline $\mathbf{0 , 0 5}$ & 0,057 & 1,50 \\
\hline $\mathbf{0 , 1 0}$ & 0,175 & 7,80 \\
\hline $\mathbf{0 , 2 0}$ & 0,155 & 2,00 \\
\hline
\end{tabular}




\subsection{Avaliação da Variação do Teor de Enxofre}

Trabalhos (Chochois et al., 2009 e Lehr et al., 2012) demonstraram que um dos maiores desafios para a produção de $\mathrm{H}_{2}$ por rota biológica é a sensibilidade da hidrogenase à presença de $\mathrm{O}_{2}$. Para solucionar este problema, a atividade no foto-sistema II da alga deve ser reduzida, de modo a equilibrar o aumento do $\mathrm{O}_{2}$ com o consumo respiratório das células. Isso ocorre quando o teor de enxofre é limitado no meio de cultivo (Melis et al., 2000). De modo a confirmar este fato, ensaios nos quais o teor de enxofre foi variado $(0,10,25$ e $50 \mathrm{mg})$ foram executados sendo apresentados na Tabela 5. Ao final, observou-se que as quantidades de biogás produzido foram maiores quando comparadas as situações supracitadas. Conforme pode ser visualizado na Figura 1, na presença de um residual de enxofre a produção de $\mathrm{H}_{2}$ é significativamente maior.

Tabela 5 - Concentração celular final e produtividade volumétrica de $\mathrm{H}_{2}$ obtidas após 5 dias de fotofermentação, sob condições diferenciadas de teor de enxofre no meio, em culturas nas quais a idade de inóculo foi de 10 dias

\begin{tabular}{|c|c|c|c|c|c|}
\hline \multirow{2}{*}{\multicolumn{2}{|c|}{ Conc. Inicial no Meio }} & \multicolumn{2}{|c|}{ Concentração celular final $(\mathbf{d})$} & \multicolumn{2}{|c|}{ Produtividade $\mathrm{H}_{2}(\mu \mathrm{mol} / \mathrm{L}$ dia $)$} \\
\hline & & $0,10(\mathrm{~g} / \mathrm{L})$ & $0,20(g / L)$ & $0,10(g / L)$ & $0,20(g / L)$ \\
\hline \multirow{4}{*}{ 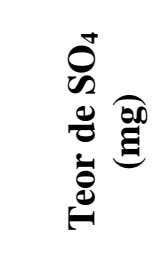 } & 0 & 0,09 & 0,30 & 0,06 & 0,50 \\
\hline & 10 & 0,08 & 0,31 & 2,09 & 1,48 \\
\hline & 25 & 0,09 & 0,46 & 0,00 & 2,26 \\
\hline & 50 & 0,10 & 0,39 & 0,00 & 1,56 \\
\hline
\end{tabular}

Para uma concentração celular inicial de $0,10 \mathrm{~g} / \mathrm{L}$, após $5 \mathrm{~d}$ de fermentação, não houve uma mudança significativa na concentração celular final, independente do teor de enxofre. Já para concentração celular inicial de $0,20 \mathrm{~g} / \mathrm{L}$, um crescimento celular progressivo foi observado com o aumento gradual do teor de enxofre no meio. Atenta-se que para um teor de $25 \mathrm{mg}$ de $\mathrm{SO}_{4}$, o maior crescimento celular, cujo desvio padrão entre as replicatas foi de $89,39 \times 10^{-3}$, foi observado. Além disso, a maior produtividade de $\mathrm{H}_{2}$ foi observada nesta condição. Percebe-se que a produção de $\mathrm{H}_{2}$ está claramente ligada a presença de uma quantidade mínima de enxofre no meio. Já a análise do metabolismo, conforme Figura 1, nos mostra que para os ácidos orgânicos, como o ácido acético, observa-se que quando há produção de $\mathrm{H}_{2}$, verifica-e uma queda da produção deste ácido e quando não há produção de hidrogênio, verifica-se um aumento na produção do mesmo. 


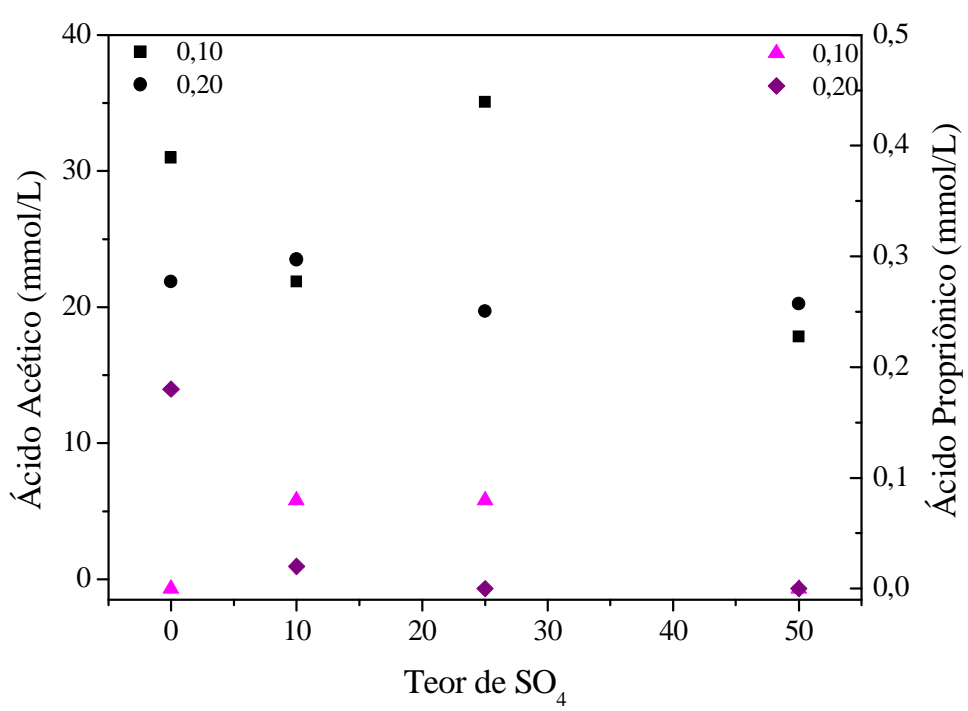

Figura 1 - Produção de ácido acético e propiônico para diferentes teores de $\mathrm{SO}_{4} \mathrm{e}$ concentrações celular iniciais de 0,10 e $0,20 \mathrm{~g} / \mathrm{L}$.

\section{CONCLUSÕES}

Diante dos resultados obtidos fica claramente demonstrada a necessidade de um melhor entendimento do metabolismo das algas verdes para que a produção de hidrogênio molecular. Em geral, hidrogênio foi produzido de forma mais acentuada a partir de uma concentração inicial de inóculo de $0,2 \mathrm{~g} / \mathrm{L}$, quando esta foi mantida em meio TAP contendo pelo menos $25 \mathrm{mg}$ de enxofre. Outra observação importante foi a verificação da capacidade metabólica da alga em produzir subprodutos do metabolismo com elevado valor agregado (ácidos orgânicos e etanol) além de diversificada aplicação tecnológica.

\section{AGRADECIMENTOS}

Os autores agradecem à FAPEMIG (Processo PCE-00089-14), CNPQ e CAPES pelo apoio financeiro e a Universidade Federal de Uberlândia, bem como a Faculdade de Engenharia Químicapelo apoio.

\section{REFERÊNCIAS}

AMIN, S. Review on biofuel and gas production process from microalgae. Energy Conversion an Mangement, Indonesia, v.5, p.1834-1840, 2009.

ANDERSEN, R. A., Algal culturing techniques, London, Elsevier Academic Press, 2005.

CHOCHOIS, V., DAUVIlle, D., BEYLY, A., TOLlEER, D., CUINE, S., TIMPANO, H., PELTRIER, G. Hydrogen production in chalmydomondas: photosystem II-dependent 
and -independent pathwaysdiffer in their requirement for starch metabolism. Plant Physiology, v. 151, p. 631-640, 2009.

DAS, D.; VEZIROGLU, T. N. Hydrogen production by biological processes: a survey of literature. International Journal of Hydrogen Energy, v.26, p.13-28, 2001.

MUS, F.; DUBINI, A.; SEIBERT, M.; POSEWITZ, M. C.; GROSSMAN, A. R. Anaerobic acclimation in chlamydomonas reinhardtii anoxic gene expression, hydrogenase induction, and metabolic pathways. The Journal of Biological Chemistry, v. 282, p. 25475-25486, 2007.

HALLENBECK, P.C.; BENEMANN, J. R. Biological hydrogen production; fundamentals and limiting processes. International Journal of Hydrogen Energy, v.27, p. 1185-1193, 2002.

KIM, J. P.; KANG, C. D.; PARK, T. H.; KIM, M. S.; SIM, S. J. Enhanced hydrogen production by controlling light intensity in sulfur-deprived Chlamydomonas reinhardtii culture. International Journal of Hydrogen Energy, v. 31, p.1585-1590, 2006.

KOSOUROV, S; PATRUSHEVA, E; GHIRARDI, M. L; SEIBERT, M; TSYGANKOV, A. A comparison of hydrogen production by sulphur-deprived Chlamydomonas reinhardtii under different growth conditions. Journal of Biotechnology, v.128, p.776-787, 2007.

KOSOUROV, S; TSYGANKOV, A.; GHIRARDI, M. L; SEIBERT, M. Sustained hydrogen photoproduction by Chlamydomonas reinhardtii: effects of culture parameters. Biotechnol Bioeng, v. 78, p. 731-740, 2002.

LEHR, F., MORWEISER, M., SASTRE, R. R., KRUSE, O., \& POSTEN, C. Process development for hydrogen production with Chlamydomonas renhardtii based on growth and product formation kenetics. Journal of Biotechnoloy, v. 162, p. 89-96, 2012.

MELIS, A., XHANG, L. P., FORESTIER, M., GHIRARLDI, M. L., \& SEIBERT, M. Sustained photo biological hydrogen gas production upon reversible inactivation of oxygen evolution in the green alga Chlamydomonas renhardtii. Plant physiology, v. 122, p. 127-135, 2000.

TAMBURIC, B.;ZEMICHAEL, F. W.; MAITLAND, G. C.; HELLGARDT, K. Parameters affecting the growth and hydrogen production of the green alga Chlamydomonas reinhardtii. International Journal of hydrogen Energy, v.36, p.7872-7876, 2011.

TEVATIA, R.; DEMIREL, Y.; BLUM, P. Kenitc modeling of photoautotrophic growth and neutral lipid accumulation in terms of ammonium concentration in Chlamydomonas reinhardtii. Bioresource Technology, v.119, p.419-424, 2012.

YANG, D.; ZHANG, Y.; BARUPAL, D. K.; FAN, X.; GUSTAFSON, R.; GUO, R.; FIEHN, O. Metabolomics of photo biological hydrogen production induced by CCCP in Chlamydomonas reinhardtii. International Journal of Hydrogen Energy, v 39, p. 150158, 2014. 